\title{
DEL RÉGIMEN NAZI AL RÉGIMEN FARMACOPORNOGRÁFICO. BIOPOLÍTICA Y DISIDENCIA SEXUAL EN DETLEVS IMITATIONEN “GRÜNSPAN" DE HUBERT FICHTE
}

\author{
Atilio Raúl Rubino \\ Universidad Nacional de La Plata \\ La Plata, Argentina \\ atiliorubino@yahoo.com.ar
}

\section{RESUMEN / ABSTRACT}

A pesar de haber pasado un poco desapercibida en su momento la novela Detlevs Imitationen "Grünspan" (1971) de Hubert Fichte es considerada hoy un hito en la narrativa de posguerra. Su protagonista doble (Detlev en el final de la guerra y los primeros años de la posguerra y Jäcki durante fines de los sesenta) permite una lectura de las formas en las que la persecución de la disidencia sexual se ha mantenido en una época de supuestos avances en el recogimiento de las diferencias. En este sentido me interesa indagar, justamente, en Detlevs Imitationen “Grünspan" la permanencia del pasado nazi en la posguerra en relación con la represión de la homosexualidad y la producción biopolítica de lo humano como lo normal y aceptado, tomando en particular el concepto de régimen farmacopornográfico que Paul B. Preciado utiliza para explicar el control y disciplinamiento de los cuerpos y las subjetividades a partir de la posguerra.

Palabras ClaVe: Hubert Fichte, novela alemana de posguerra, disidencia sexual, estudios queer.

From the Nazi Regime to the Pharmacopornographic Regime. Biopolitics and SEXUal Dissidence in DetleVs Imitationen “GrünSPan” by Hubert Fichte

Despite initially going somewhat unnoticed, today, the novel Detlevs Imitationen "Grünspan" (1971) by Hubert Fichte is seen as a milestone in the post-war narrative. Its double protagonist (Detlev at the end of the war and the first years of the post-war period, and Jäcki during the late sixties) allows for a reading of the ways in which the persecution of sexual dissidence continued in a time of apparent progress in the gathering of differences. In this sense, I am 
interested in analyzing, particularly in Detlevs Imitationen "Grünspan", the permanence of the Nazi past in the post-war period in relation to the repression of homosexuality and to the biopolitical production of the human as what is normal and accepted. To this end, I shall especially take the concept of Pharmacopornographic Regime, coined by Paul B. Preciado to explain the control and the disciplining of bodies and subjectivities from the beginning of the post-war period.

KEYWORDS: Hubert Fichte, German post-war novel, Sexual Dissidence, Queer Studies.

Recepción: 18/08/2018

Aprobación: 20/12/2018

\section{DEL RÉGIMEN NAZI AL RÉGIMEN FARMACOPORNOGRÁFICO}

En su corta vida, Hubert Fichte (1935-1986) escribió más de 50 libros, además de artículos, entrevistas, intervenciones y guiones radiales en donde ahonda no solo en la realidad alemana sino latinoamericana y africana (Hergemöller). En efecto, la obra de Fichte es importante en dos sentidos. Por un lado, sus trabajos en torno a la etnopoesía prefiguran en cierto sentido debates sobre hibridez y habla subalterna (Gundermann $)^{1}$. Asimismo, Fichte es el primer autor alemán en tratar la homosexualidad como práctica y como identidad de una forma sumamente abierta y explícita. Nacido en Perleberg, Brandeburgo, dos años antes de la llegada de Hitler al poder y muerto de VIH-SIDA tres años antes de la caída del muro, Hubert Fichte (1935-1986) es uno de los autores alemanes de posguerra sobre el que más se ha escrito acerca del tema literatura y homosexualidad (Hergemöller) y el escritor homosexual de lengua alemana que con mayor radicalidad ha indagado en una construcción de un Yo narrativo $s c h w u l^{2}$ (Popp 256). Sus primeras novelas, Das Waisenhaus

\footnotetext{
Es importante su interacción con las culturas latinoamericanas, pues implica la ruptura y discusión con las perspectivas antropológicas como las de Levi-Strauss. Fichte se adelanta así, a un discurso antiorientalista. En Brasil se relaciona con el movimiento poético antropófago de Oswald de Andrade, que resulta de influencia para su obra, así como las investigaciones sobre la magia y las culturas consideradas primitivas. En este sentido, su obra, que nace en los años sesenta, época de nuevas búsquedas postvanguardistas, conecta con las vanguardias históricas de principios de siglo XX pero, más que con las vanguardias europeas, se trabaja con las latinoamericanas, con el negrismo, el canibalismo, la antropofagia (Gundermann).

2 La palabra Schwul en Alemania es el término con el que se autoproclaman las identidades disidentes a partir de los años setenta. Así como "queer", palabra con la que convive después de los noventa, se trata de un insulto resignificado, que puede ser traducido como "puto".
} 
(1965), Die Palette (1968), Detlevs Imitationen «Günspan» (1971) y Versuch über die Pubertät (1974) conforman un ciclo pseudoautobiográfico que puede considerarse en la tradición del Bildungsroman, aunque más que afirmar la génesis de una identidad, Fichte deconstruye la subjetividad del/de los protagonista/s, mediante una serie de juegos poéticos que desarman el "yo" que enuncia. De esta forma, se cuestionan asimismo las identidades como algo estable y fijo, fundamentalmente la identidad homosexual, erosionando, al mismo tiempo, la forma de la novela, propia del siglo XIX y de una cosmovisión moderna. Considerado por Robert Gillett ("Writing queer" 43) como uno de los autores proto-queer junto a Jean Genet, Hubert Fichte es uno de los primeros autores alemanes en retratar una variedad de prácticas y formas de vida disidentes, que escapan no solo a la norma de la sociedad heterosexual sino también a los estereotipos masivos de la comunidad gay. En este sentido me interesa indagar, justamente, en su tercera novela, Detlevs Imitationen "Grünspan", la permanencia del pasado nazi en la posguerra en relación con la represión de la homosexualidad y la producción biopolítica de lo humano como lo normal y aceptado. Las novelas de Hubert Fichte anticipan algunos de los temas de lo queer-aunque tampoco resultan ajenas a los debates de los años setenta-. Con su forma poética y vanguardista, que rompe con la novela tradicional, con el Bildungsroman y con el lenguaje, propiamente dicho, Detlevs Imitationen "Grünspan" permite leer algunos cuestionamientos a la moralidad, a la sexualidad y el género binarios y, lejos de quedarse en este cuestionamiento, aparecen vislumbradas algunas formas de resistencia al poder y de puntos de fuga a la sexualidad que serían teorizadas décadas después por los sectores más radicales de la teoría queer, una revolución micropolítica y microcorporal a partir del uso desestabilizante de las hormonas o de las operaciones quirúrgicas, el ejercicio de la prostitución como emancipación de la cárcel del cuerpo, la performance drag como forma subversiva de sexo-género y, fundamentalmente, un cuestionamiento que podemos leer hoy como post-identitario a la producción capitalista de subjetividades.

Según Jens Dobler, también era usada por lesbianas como identidad. Se trataba en ambos casos de una forma de contrarrestar la normalidad relacionada con la homosexualidad. Implicaba una autodefinición, a partir del uso de un insulto (Schimpfwort) para poner en primer plano y exagerar la estigmatización y la estereotipación y generar dentro de la Schwulenbewegung una nueva y colectiva interpretación, generar un "Wir-Kollektiv" (nosotros colectivo) (Pretzel y Weiss 19) y, de ese modo, evitar las definiciones desde afuera. 
Gillet considera esta novela un hito de la narrativa alemana de posguerra, a pesar de no ser tan conocida o influyente. Por eso la elige para su contribución a la compilación Landmarks in the German Novel y arguye varias razones para esa decisión, según él, por cómo conecta 1943 y 1968, por el tratamiento de la sexualidad, por la deconstrucción de la autobiografía y porque también prefigura "that body of activism, writing and theory which has become known as 'Queer"' (Gillett, "Ein Verständigungstext" 59). En consecuencia, me interesa indagar en este artículo el contrapunto de los dos personajes protagonistas, Detlev y Jäcki, y las dos épocas en las que viven, el inicio de la posguerra y finales de los años sesenta. En este salto temporal lo que se puede vislumbrar es, justamente, que respecto a la disidencia sexual la ideología del régimen nazi ha prevalecido, se ha refinado, se ha vuelto más sutil. A pesar de los enormes avances que las décadas del sesenta y el setenta significaron para la comunidad gay y schwul, las formas de dominación se refinan bajo la forma de nuevas normalizaciones, que delimitan lo humano de lo no humano, las vidas vivibles y las que no pueden ser vividas o no importan. Es decir, se trata de lo que Deleuze ha denominado sociedades de control y Paul B. Preciado reformuló como régimen farmacopornográfico.

Si el concepto de sociedad disciplinaria de Foucault se aplicaba al siglo XIX, algunos autores coinciden en que debería ser reformulado para pensar mejor la situación a fines del siglo XX. Así, en la posdata a Mil mesetas de 1990, Deleuze habla de sociedades de control. Según Deleuze, la lógica ya no es la del encierro y vigilancia de la fábrica, sino la del control continuo que implica la competencia y el mérito de la empresa que impone "una modulación de cada salario, en estados de perpetua metastabilidad que pasan por desafíos, concursos y coloquios extremadamente cómicos" (Deleuze). Paul B. Preciado retoma esta teorización de Deleuze pero prefiere denominar farmacopornográfico al régimen actual de control de cuerpos y subjetividades, pues en él ya no se controla a los sujetos mediante la disciplina externa sino que las tecnologías de subjetivación son internas, micro y protésicas, es decir, se convierten en cuerpo: "Si en la sociedad disciplinar las tecnologías de subjetivación controlaban el cuerpo desde el exterior como un aparato ortoarquitectónico extremo, en la sociedad farmacopornográfica, las tecnologías entran a formar parte del cuerpo, se diluyen en él, se convierten en cuerpo" (Preciado, Testo 72). Preciado ve al porno y la industria farmacológica como modelos utópicos de toda empresa: la lógica excitación/frustración del porno y la lógica de la medicina ya no para curar enfermedades sino para concebirlas, crearlas o, en realidad, construir lo humano, delimitar lo normal. Para Preciado, el control 
de la subjetividad se lleva adelante por un mecanismo microprotésico que es a la vez material (fármaco) y simbólico-mediático (porno):

El contexto somatopolítico (de producción tecnopolítica del cuerpo) posterior a la Segunda Guerra Mundial parece estar dominado por un conjunto de nuevas tecnologías del cuerpo (biotecnologías, cirugía, endocrinología, etc.) y de la representación (fotografía, cine, televisión, cibernética, etc.) que infiltran y penetran la vida cotidiana como nunca habían hecho (Preciado, Testo 70-72).

La acción sobre el cuerpo ya no se da mediante la prisión, la escuela o la fábrica. Si el modelo ahora es la empresa, como afirma Deleuze, Preciado va más lejos: se trata de acciones "microprotésicas". El modelo de la empresa ya no es la producción sino la venta, pero se trata también de venta, producción y circulación de información mediática, que se hace carne, de información genética, biotecnológica, hormonal. Este nuevo régimen también tiene características globales. Es por eso que puede ser pensado como parte de lo que Félix Guattari llama Capitalismo Mundial Integrado y porque también "tiende a que ninguna actividad humana, en todo el planeta, escape a su control" (Guattari 57). Este capitalismo sobrecodifica todas las actividades, los flujos, el poder (Guattari 75). En ese marco, la matriz heterosexual de inteligibilidad forma parte integral del capitalismo como máquina abstracta de sobrecodificación de cuerpos, de relaciones, de vidas, de subjetividades, de existencias y de experiencias.

En este contexto podemos pensar el surgimiento de la perspectiva queer hacia la segunda mitad de los años ochenta como una continuidad (Preciado "Terror anal") más que como una ruptura con los movimientos de liberación gay-lésbica de los setenta. Así, la novela de Fichte da cuenta de una época de tensión entre diferentes formas residuales y emergentes de entender y de vivir las sexualidades, en donde se solapan modos residuales con recientes avances en la liberación y visibilización gay que, a su vez, traen ya una incipiente normalización que se instaura de forma transnacional mediante la imposición del modelo gay norteamericano. En este sentido, la conexión entre la posguerra y los años setenta significa desilusión porque implica, como sostiene Preciado (Testo), que las formas de dominación se vuelven más sutiles.

Detlevs Imitationen "Günspan" puede considerarse una continuación de sus dos novelas anteriores, Das Waisenhaus (1965) y Die Palette (1968). Si bien se evidencia una erosión de la diégesis propia de la novela moderna, Detlevs 
Imitationen "Grünspan" se ocupa de la vida de su protagonista desde donde la dejó su primera novela Das Waisenhaus. Ya fuera del orfanato, Detlev vuelve a Hamburgo con su familia, en los últimos años de la guerra y los primeros de la posguerra, desde 1943 hasta 1948, es decir desde la edad de 8 hasta la de 13 años. Pero la historia de Detlev es contrastada con un contrapunto con la de otro personaje, Jäcki, que también es el protagonista de su segunda novela, Die Palette, y, de hecho, sigue también su vida, en la tercer década de la misma, después de lo que ocurrió en la novela anterior, que finaliza con el cierre y la última visita de Jäcki al bar schwul "Die Palette" en 1968.

Compuesta a partir de la técnica del collage y el montaje, la novela de Fichte resulta bastante inusual. A su vez, en ella aparece una mezcla de voces y discursos superpuestos, fragmentarios, costituyendo así una especie de pastiche de voces y textos, en la que resuena cierta idea de cultura como un palimpsesto. La novela no está organizada estrictamente en capítulos (aunque algunos críticos sí los consideran como tales), sino en secciones de extensión variable. Específicamente, se trata de 144 apartados, algunos de los cuales son muy breves, de pocas líneas, y otros de varias páginas. Como dije, entre los distintos apartados se genera un contrapunto entre la infancia de Detlev al finalizar la guerra y la adultez de Jäcki a fines de los sesenta, quien en 1968 podría tener aproximadamente 33 años. Es decir, se trata de dos vidas en paralelo, contemporáneas ¿o quizá de la misma?

Desde el título la novela plantea este contrapunto, esta superposición de dos personajes y dos épocas históricas aunque, como veremos, podría tratarse del mismo personaje, ya que la identidad y la relación entre Detlev, Jäcki y el yo-narrador aparece problematizada y cuestionada o, incluso, resulta inidentificable (Madsen 196). Por un lado, tenemos la infancia y preadolescencia de Detlev, niño actor que aprende mediante la imitación (performance, actuación, impostura, identidad) ${ }^{3}$ cómo ser un hombre, es decir, cómo construir una masculinidad hegemónica y heteronormativa no solo mediante una violencia patriarcal contra las mujeres sino a través de la represión de los posibles deseos homosexuales. La narración sigue, por un lado, la vida de Detlev, sus primeras incursiones y relaciones con el teatro

\footnotetext{
Según Gillett, la idea de imitación en la historia de Detlev tiene varias implicaciones; en primer lugar, al problema de la mímesis y la posibilidad de representar la realidad, por otro lado, al proceso de aprendizaje y socialización del niño, pero también a una técnica de actuación (Gillett, "Huberts Imitationen” 303).
} 
de Hamburgo en el período antes mencionado, de 1942 hasta 1948, y, por otro, el deambular de Jäcki, después del cierre del bar schwul "Die Palette", por espacios de sociabilidad disidente, entre otros, el del bar psicodélico "Grünspan", espacio típico del Hamburgo de fines de los sesenta, que forma parte del submundo disidente, de los suburbios, en los que se mueve Jäcki y en donde la sexualidad encuentra su punto de fuga.

\section{LAS IMITACIONES DE DETLEV Y LA SEXUALIDAD APRENDIDA}

En una de las primeras escenas de la novela presenciamos a Detlev fantaseando con la posibilidad de ser llevado a un campo de concentración y torturado allí. Aunque luego se une a las juventudes hitlerianas, Detlev tiene sangre judía por parte de padre. Por esta razón, el campo de concentración es un horizonte a temer, pero asimismo, a medida que avanza su infancia y preadolescencia, los deseos homosexuales, ya finalizada la guerra, lo van a hacer pensar también en campos de concentración. Se trata de una sexualidad todavía en la posguerra imposible de concebir. La infancia de Detlev está marcada por el aprendizaje de la masculinidad hegemónica. Ese es el principal sentido de sus "imitaciones". De esta forma, la masculinidad, en la novela de Fichte, no es una naturaleza del hombre, sino que se aprende y consiste, básicamente, en dos puntos que podemos identificar con el (hetero)patriarcado, por un lado, el sometimiento de la mujer, la violencia machista y misógina y el uso de la mujer como objeto y, por otro, la represión de la homosexualidad. Así, Detlev aprende, por ejemplo, cómo tener relaciones sexuales: “_ Tienes que clavárselo en la concha y sacarlo de nuevo y clavarlo de nuevo y al final haces pis adentro y así salen después los niños de las mujeres desde el culo" [“Du mußt ihn in die Fotze reinpuhlen und ihn wieder rausholen und ihn wieder reinpuhlen und zum Schluß pißt du drauf und so kommen die Kinder dann bei der Frau aus dem Arsch"] (133-4) ${ }^{4}$. Las primeras aproximaciones de Detlev a la sexualidad son discursivas, didácticas. Pero también hay un contacto con ella a partir de la experiencia y del deseo que va a entrar en tensión con la dimensión discursiva de la misma. A partir de una vinculación intertextual

$4 \quad$ Las traducciones que se ofrecen de la novela son propias, se contemplan en notas al pie o entre corchetes los textos originales en alemán. 
con La Marquesa de O (Die Marquise von O..., de 1808) de Heinrich von Kleist, la relación sexual comienza a pensarse como violación y aparece varias veces la pregunta acerca de cómo violar a alguien ["-Wie vergewaltigt man jemanden (p. 135 y 136)], a partir de la cual se vincula claramente la violencia del patriarcado con la represión de la homosexualidad, desde las voces que explican cómo es la vida adulta, sexual, heteronormativa:

- Uno la amenaza, la golpea hasta tirarla. Uno -una mujer es forzada a rendirse. Uno la viola.

- ¿Cómo viola uno a una mujer?

- Violándola, forzándola a rendirse.

- ¿Cómo uno llega a rendirse?

- Estás hablando en círculos.

- ¿Ya lo has hecho alguna vez?

- El órgano sexual del hombre se pone muy duro y rojo y se queda erguido. El hombre excitado introduce así el órgano sexual en la mujer y mueve su bajo vientre hacia adelante y hacia atrás.

- ¡Un hombre adulto!

- Hace esto hasta que descarga el semen

- ¿El oficial en "La Marquesa de O.” también?

- Sí. Y Volpone seguramente también. (...)

- ¿Por qué el rizado tramoyista no debe hacerme cosquillas?

- Hay hombres que se sienten atraídos por el mismo sexo.

- ¿Goethe también?

- ¡Santo cielo!

- ¿Y en dónde hay que meterla?

- Está prohibido y se castiga duramente. Y es nocivo. Se llama homosexual. Aunque también se dice de Patroclo, que es una puta y se acuesta con Aquiles.

- ¿Qué es una puta?

- Alguien que lo hace por dinero.

- ¡Hay un montón de cosas de las no tenía la menor idea! ¡Homerosexual!

Entonces Hector viene hacia mí siempre cuando Aquiles con las inaccesibles manos el espantoso sacrificio de Patroclo ofrece - ¡Grandioso! (135-6) ${ }^{5}$ gezwungen. Man vergeht sich an ihr. / - Wie vergeht man sich an einer Frau? / - Indem man 
Se trata de un momento de doble descubrimiento. Al discurso de la dominación de la mujer le corresponde la experiencia inicial de la homosexualidad por parte de Detlev (Vocca 135). Es decir, aquí también aprende sobre el tabú de la homosexualidad. Se trata de dos caras de la misma moneda, el (hetero) patriarcado. Pero la literatura permite, asimismo, una doble lectura, heteronormativa y disidente. Patroclo o Goethe son ejemplos literarios de lo prohibido, del tabú de la sexualidad, pero también se pueden constituir en modelos a seguir, en elementos que permitan un agenciamiento disidente, una identificación. Detlev aprende, asimismo, que no debe dejarse tocar por hombres. Lo mismo puede decirse, con un signo contrario, de Die Marquise von $O \ldots$, es decir, se trata ahora sí de una lectura heteronormativa que permite explicar la sexualidad adulta como violación. Pero el personaje, a partir de la pregunta "Wie gibt man sich hin?" [¿Cómo uno llega a rendirse?], vacila en la identificación entre la masculinidad heteronormativa y la pasividad del que es sometido. Asimismo, mediante un Lapsus en la voz de Detlev se genera una torsión de la identificación del violador (el oficial ruso de Die Marquise von $O \ldots$...) a la mujer violada (La marquesa): "y yo la Marquesa de O., quiero decir, el educado oficial francófono de La Marquesa de O." [und ich die Marquise von O., ich meine, der gebildete, französisch sprechende Officier in der "Marquise von O."] (141). Detlev trasviste el texto teatral de Kleist al identificarse con el personaje femenino (Vollhaber 198). El final de la novela, su último párrafo, cierra justamente con la repetición de este Lapsus: "Detlev reflexiona que ahora ya no es más sólo un niño actor, sino que podría ser la Marquesa de O., él cree, como Hermann Lenschau podría interpretar al oficial ruso en La Marquesa de O.” [Detlev überlegt, dass er jetzt nicht mehr nur

sie vergewaltigt, Indem man sie zur Hingabe zwingt. / - Wie gibt man sich hin? / - Du redest immer im Kreise. / - Hast du es auch gemacht? / - Das Geschlechtsteil des Mannes wird ganz steif und rot und steht aufrecht. Der erregte Mann führt so das Geschlechtsteil in die Frau ein und bewegt seinen Unterleib hin und her. / - Ein erwachsener Mann! / -So lange, bis er den Samen entlädt. / - Der Offizier in der "Marquise von O." auch? / - Ja. Und Volpone möchte es auch gerne. (...) / - Warum soll der lockige Bühnenarbeiter mich nicht durchkitzeln? / - Es gibt Männer, die fühlen sich zum gleichen Geschlecht hingezogen. / - Goethe auch? / - Um Himmels willen! / - Und wo wollen die es hinstecken? / - Es ist verboten und es wird hart bestraft. Und schädlich. Es heißt homosexuell. Wenngleich auch von Patroklos gesagt wird, er sei eine Mannshure und liege bei Achill. / - Was ist eine Hure? / - Eine, die es für Geld tut. / - Das gibt es alles und ich hatte keine Ahnung davon. Homersexuell! / Will sich Hektor ewig von mir wenden, / Wo Achill mit den unnahbaren Händen / Dem Patroklos schrecklich Opfer bringt? / - Herrlich! (135-6) 
rein Kinderdarsteller ist, sondern, dass er die Marquise von O. spielen könnte, er meint, wie Hermann Lenschau der russische Offizier in der "Marquise von O.” spielen könnte.] (255). Su identificación identitaria tambalea entre lo masculino y lo femenino, entre lo activo y lo pasivo, entre lo violento y lo sumiso. Todavía no se ha convertido en Jäcki, todavía no ha encontrado puntos de fuga a la racionalidad binaria de sexo-género, lo que Wangenheim (1980: 90) considera como el momento de conciencia de su bisexualidad. Esta doble identificación marca una sexualidad fluctuante, no identitaria, que se va constituyendo mediante los dispositivos de disciplinamiento. Por otro lado, el tema de la culpa de ser madre soltera en la época de Die Marquise von $O$... es comparable a la culpa de la homosexualidad en el siglo XX, en la posguerra (Klaus 124) y, a su vez, la fantasía de ser violado de Detlev le evita la culpa de la homosexualidad, de ser agente de su deseo.

Esta educación en la versión más violenta y misógina de masculinidad heterosexual está tensionada con sus propios deseos sexuales, que plantean una línea de fuga a esta normativización. Es interesante, en este sentido, que el deseo homoerótico de Detlev comienza con la finalización de la guerra, ya que empieza a sentirse atraído por los soldados de la ocupación. Entre ellos, fundamentalmente, su deseo se torna hacia un marinero de nombre Paul (56). Aunque al mismo tiempo planea casarse (59), es decir, hay una imposibilidad de llevar adelante este deseo. Se plantea así una tensión entre las posibilidades reales y el deseo, que siempre implica, en este sentido, un resto, algo que no puede ser aprehendido del todo, que escapa al sentido normativo de la familia, no solo para el nazismo sino también, y con más ímpetu, para la sociedad de la posguerra. Desde el inicio tiene la fantasía de ser torturado en un campo de concentración, tanto por su sangre impura como luego por sus deseos homosexuales. Lo que constituye la lógica del deseo en Detlev es esta tensión entre lo aprendido y lo que su cuerpo y fantasía busca, lo que resulta no solo imposible sino, en algunos casos, ininteligible. Parte de su educación sexual también consiste, justamente, en aprender esta prohibición ("Es ist verboten und es wird hart bestraft. Und schädlich"). Su educación sexual le impide aprehender lo material de su deseo, es decir, lo que constituye una fuga respecto a la sexualidad aprendida, al sistema de coherencia compulsiva del heteropatriarcado. En este sentido, también, podemos pensar en un esquema de inteligibilidad binario que no solo ubica en polos opuestos lo masculino/femenino en relación con actividad/pasividad, sino en un diseño binario SM: activo/pasivo, dominador/dominado, violador/ violado, violencia/sumisión. En su deseo ocupa un lugar importante la fantasía de sometimiento: "Si Dicker y Harald por lo menos me metieran sus palos 
(Stöcke) por atrás (...). Es una cuestión de fuerza mayor" ["Wenn Dicker und Harald mir nur wenigstens ihre Stöcke hinten reinstecken würden (...). Das ist höhere Gewalt"] (206). Como comenta Vocca, Detlev internaliza los principios de una cultura violenta porque está aprendiendo a superar el lado femenino, "pasivo", de sí mismo y a categorizar su mundo en aquellos que dominan y aquellos que se someten (Vocca 131).

\section{JÄCKI Y LA DISIDENCIA DEL "GRÜNSPAN"}

El trayecto de Jäcki en Detlevs Imitationen “Grünspan” continúa después de lo ocurrido en la novela anterior, Die Palette, que finaliza con el cierre del bar schwul de ese nombre en Hamburgo. Así como el deseo de Detlev se fija sobre todo en el marinero Paul, las secciones destinadas a Jäcki están marcadas por el deseo hacia Jeff, un negro que representa un estereotipo de masculinidad quizá asimilable a los cuerpos deseables de los dibujos de Tom de Finlandia. Así, por ejemplo, este contrapunto hace que, después de la torpe lección de Detlev, le siga una descripción en detalle de la pornografía de Tom de Finlandia (Gillett, "Fichte, Detlevs Imitationen" 53). En la novela de 1968 el bar schwul, subterráneo, se convierte en un refugio del mundo exterior, aunque acosado por las racias policiales y otros controles externos, allí se da una liberación del deseo y del placer. La deriva de Jäcki en Detlevs Imitationen Grünspan continúa por otros espacios de socialización disidente en Hamburgo. Aquí tenemos la otra parte del nombre de la novela, "Grünspan", uno de los espacios de socialización disidente por los que va a pasar después del cierre de "Die Palette". Según Gillett, "Grünspan” en el título de la novela no refiere solo al bar homónimo en Hamburgo sino también al veneno verdigris usado como reemplazo del oro en los monumentos de la posguerra (Gillett, "Writing queer" 48). También implica mezclas, unión de contrarios, en ese sentido bisexualidad, androginia, como formas de fuga al binarismo sexual. También para Jäcki estos espacios constituyen momentos de aprendizaje y crecimiento, mediante lo que entendíamos con Detlev como imitación. Pero aquí los modelos a seguir van a ser los de la disidencia. Estos espacios están ocupados por prostitutas, chulos y drag-queens. Otro lugar que Jäcki frecuenta es el "Palais d'amour", una especie de prostíbulo pornográfico performático. Pestañas postizas, brillantina, tintura del vello púbico, ametralladoras, pelucas, extensiones del cabello, dildos, ropa de cuero, zapatos de taco alto y personajes como Reimar Renaissancefürstchen 
o Goldhämsterlein completan el universo de este submundo en donde la feminidad es una performance, pero también la masculinidad. En este espacio hay pornografía audiovisual casera para los clientes voyeur y performance pornográficas (o que, hoy, podríamos considerar postpornográficas). Pero también se da cuenta de la continuidad del acoso policial que todavía en los sesenta y principios de los setenta perseguía la disidencia. De hecho, en ocasiones se narra el ingreso de la policía con perros y la pesquisa en busca de drogas y pornografía.

Es interesante pensar en una obra de teatro que escribe Jäcki. La sección 89 va intercalando a la narración algunos fragmentos de esta obra. Los actos nos presentan también performances disidentes y rupturistas, en donde se vincula de forma anacrónica la violencia del régimen nazi con su continuidad en la actualidad de fines de los sesenta. Asimismo, las continuas alusiones a dildos, representaciones y sustitutos del pene (Gummispielermann, p. 177, entre otras menciones) y la importancia que se les conceden en las descripciones de estos espacios lleva a pensar en los análisis de Paul B. Preciado (Manifiesto) sobre el suplemento derridiano y el cuerpo prostético. El acto tres, por ejemplo, presenta a una travesti "con un gran objeto de culto de goma" ["mit einem großen Kultgegenstand aus Gummi"] que luego "se mete una salchicha de goma de medio metro entre sus cicatrices frescas" ["steckt sich schließlich einen halben Meter rosa Gummiwurst zwischen ihre frischen Narben"] (144). Pero también la masculinidad deviene aquí una performance, en términos de lo que Judith Butler en su teoría de la performatividad llama parodia de género. Jäcki conoce allí a Jeff, quien, con sus "abrumadoras columnas de carne" ["den niederschmetternden Fleischsäulen"] y su "especie de hocico negro-violeta" ["eine Art schwarz-violetter Rüssel"], su "gigante pito con los gigantes huevos" ["die Riesennille mit den Rieseneiern"] (144), representa también la exacerbación de la masculinidad. Si bien es difícil establecer una estricta estructura diegética en la novela, ya que se mezcla con derivas poéticas, pastiche de voces y rupturas del sentido y del lenguaje, se podría pensar que así como el arco narrativo de Detlev está marcado por la tensión entre su educación sexual heteronormativa y el deseo homosexual que comienza a sentir después de la guerra, también el trayecto narrativo de Jäcki está marcado por su deseo hacia el africano Jeff, que se concreta hacia el final, mediante el ejercicio de la prostitución por parte de Jäcki. Jeff representa aquí esa masculinidad exacerbada por la que se siente atraído pero esto también es una performance, una imagen, un estereotipo o, en palabras de Jäcki, una mentira: 
-No sé nada de Jeff. Sé demasiado. Cada frase es una mentira (...). Los movimientos de su proporcionado cuerpo de color de ébano son mentira. Miente cuando gime como una niña mentirosa. Creo que a veces él sólo hace como si estuviera erecto. Por otro lado, es también una especie de estado ideal. $(119-20)^{6}$

La identidad es Lüge, una mentira. Pero también lo es el cuerpo, la erección de Jeff, por ejemplo, si puede ser reemplazada por un dildo de goma, como los de las performances teatrales. Si tomamos las teorizaciones de Preciado sobre régimen farmacopornográfico y sobre sexualidad prostética podemos pensar esa sexualidad de los sesenta como postpornográfica, es decir, aquella que desafía el régimen (Tercer Reich y farmacopornográfico) y que se constituye como una resistencia al mismo y como agenciamiento, punto de fuga a la sexualidad normativa. En este sentido, no solo se trata de una sexualidad performática, sino también prostética, que pone en evidencia que toda la sexualidad y la corporalidad es prótesis. El cuerpo de Jeff no solo está idealizado, sino que es prótesis. Su pene negro y grande no es más que una imitación del dildo que construye al pene como original. En la novela de Fichte, así como en la teoría prostética de Preciado, no hay un original asimilable al pene natural. Todo es dildo, extremidades de plástico que instauran la ficción de un original de carne. Los cuerpos, como el de Jeff, performáticos y protésicos.

\section{NORMALIDAD BIOPOLÍTICA Y HOMOSEXUALIZACIÓN MUNDIAL}

Es interesante pensar que al contrastar entre estos dos períodos -la época de Detlev y la de Jäcki- lo que resulta es una desilusión respecto de los cambios sociales. Las referencias a los campos de concentración, por un lado, vinculan las dos épocas, ya que se difuminan en una variedad de significaciones que exceden la del pasado reciente. Por un lado, se trata del pasado reciente de Alemania todavía no resuelto; hay que pensar por ejemplo en que el abuelo de

\footnotetext{
$6 \quad$ “- Ich weiß nichts von Jeff. Ich weiß viel zu viel. Jeder Satz ist eine Lüge (...). Die Bewegungen seines ebenmäßigen, ebenholzfarbenen Körpers sind Lüge. Er lügt, wenn er wie ein verlogenes Mädchen stöhnt. Ich glaube manchmal, er tut nur so, als ob er erigiert. Andrerseits ist es natürlich auch eine Art Idealzustand". (119-20)
} 
Detlev es afiliado al partido y tiene que ocultarlo después de la guerra o que Rolf Lüders es un homosexual que ha sobrevivido al nazismo por denunciar a otros homosexuales. Pero al mismo tiempo los campos de concentración devienen significativos en la continuidad que plantean con el presente de los sesenta y de los setenta, no solo por el recuerdo de las víctimas y la convivencia con personas que han pasado por campos de concentración sino también porque deviene metáfora de una condición interna, algo así como un clóset, un armario, pero también porque hay una continuidad de los campos de concentración en la organización biopolítica. Podemos pensar con Paul B. Preciado que en este sentido también el deseo está atravesado por un dejar vivir/hacer morir, por producción/disciplinamiento de vidas farmacopornográfico.

En 1968 se celebra el aniversario de lo que se conoce como operación Gomorra, el bombardeo de Hamburgo de 1943 por parte de las tropas aliadas. Este hecho y su aniversario generan una deriva que va de las víctimas de los campos de concentración a las víctimas de los bombardeos aliados en Hamburgo. En esta parte, el lenguaje se desarma y ya no hay forma de expresar el horror. El episodio se convierte así en un problema de lenguaje y una pregunta sobre la identidad del escritor (Böhme). A su vez esta deriva vincula el nombre de este bombardeo, Gomorra, con Sodoma y el término relacionado, sodomita, desde una visión que podemos entender como biopolítica para pensar los distintos regímenes de hacer vivir y dejar morir:

Gomorra

- Miedo

Cualquier empujón puede significar la muerte. La denuncia era suficiente. Uno no puede ir a prisión. Para que un proceso pudiera evitarse, uno desaparecía en un campo de concentración, como solía ocurrir.

Sir Arthur, abrimos el capó de nuestro coche. Sí, este mayo es fresco. Sin embargo, el rododendro blanco ya está florecido. Pero nuestros parques-sodomitas están vacíos de noche. Nadie celebra este 17 de mayo. Entender la sutileza: 17.5. Desde que el parágrafo ha sido abolido, la policía de Hamburgo triplicó sus patrullas. No hay ningún urinario o arbusto más que no esté vigilado. Los jardines florecientes de Hamburgo. Los pulmones verdes de la ciudad.

En 1934 se cambió al director de la prisión de Fuhlsbüttel. En lugar de un hombre de la SS, un hombre de la policía de Hamburgo recibió el puesto. Para los presos políticos comenzó un período paradisíaco. 
El nuevo comandante tenía una afición por los presos políticos. Las cosas fueron tan lejos que en una pasada de lista le gritó a un sodomita que estaba parado entre los presos políticos:

- ¿Quieres desaparecer completamente de entre mis decentes políticos, cerdo marica?

God bless the Queen, Sir Arthur! (39)

Como comenta Bandel, Jäcki marca la continuidad fascista de la persecución de los homosexuales (Verfolgung der Schwulen) como estructura de fondo de la sociedad burguesa. (Bandel 181). Los campos de concentración han desaparecido, pero no la persecución policial y la limpieza de la suciedad sexual de los parques (Böhme 181). Con la abolición parcial del parágrafo 175 en $1969^{8}$, según Fichte, se recrudeció la persecución policial a la homosexualidad $\mathrm{y}$, en particular, a los lugares de socialización y de cruising. Por otro lado, Jäcki en 1968 se encuentra realizando una investigación antropológica sobre la violencia a partir de la exhumación de los cadáveres de las víctimas de los bombardeos en Hamburgo. Las muertes de los bombardeos se convierten en números, estadísticas, fórmulas químicas. Lo que prima en la investigación

\footnotetext{
"Gomorrha. / - Angst. / Jeder Stoß konnte den Tod bedeuten. Denunziation genügte. Man kam nicht ins Gefängnis. Damit ein Verfahren umgangen werden konnte, verschwand man in einem KZ oder KL, wie Sie wollen. / Sir Arthur, wir öffnen das Verdeck unsres Wagens. Ja, dieser Mai ist kühl. Trotzdem ist der weiße Rhododendron schon aufgeblüht. Aber unsre Sodomiten Parks sind leer nachts. Niemand feiert diesen 17. Mai. Sie verstehen die Subtilität: 17.5. Seit der Paragraph aufgehoben worden ist, verdreifacht die Hamburger Polizei ihre Streifen. Es gibt kein Urinier mehr und keinen Busch, die nicht bewacht sind. Hamburgs blühende Parks. Die grünen Lungen der Stadt. / 1934 wechselte der HL-Kommandant von Fuhlsbüttel. Statt eines SS-Mannes erhielt ein Mann der Hamburger Polizei den Posten. Für die politischen Häftlinge begann eine paradiesische Zeit. Der neue Kommandant hatte ein Faible für die politischen Häftlinge. Das ging so weit, dass er einen Sodomiten, der sich unter die Politischen beim Appell gestellt hatte, anbrüllte: / - Willst du schwule Sau wohl aus meinen anständigen Politischen verschwinden. / God bless the Queen, sir Arthur!” (39).

El mismo año de la rebelión de Stonewall en Estados Unidos en la República Federal de Alemania se despenaliza la ley que prohibía las relaciones sexuales entre hombres (el parágrafo 175 del código penal). Claro que esta despenalización es solo parcial, ya que éstas dejaban de ser ilegales para personas mayores a los 18 años, en tanto las relaciones heterosexuales eran legales desde los 14 años de edad. De cualquier forma, esto posibilitó las primeras organizaciones militantes alemanas en torno a lo que se conoció como la Schwulenbewegung (el movimiento de liberación gay-lésbica).
} 
antropológica sobre la violencia es la aparición de discursos médicos ${ }^{9}$. En ese sentido, se constituyen en vidas que ya no importan, como las vidas de los homosexuales, todavía hacia fines de los sesenta silenciados, invisibilizados y negados como víctimas del nazismo, pero también de la sociedad de posguerra, en donde la disidencia no solo seguía siendo penada y censurada moralmente sino deliberadamente perseguida. Jäcki humaniza las víctimas, vuelve visible así el régimen biopolítico que perduró después de la guerra. Los cuerpos analizados por Graeff en las autopsias se constituyen, así, en vida desnuda (Agamben), vidas humanas convertidas en materialidad desechable, analizable, en número, cifras, fórmulas. Y es Jäcki el que identifica allí los residuos del pensamiento nazi (Gillett, "Fichte, Detlevs Imitationen" 49). Podemos pensar desde una perspectiva biopolítica la vida en la actualidad de Jäcki como un campo de concentración. De hecho, el sentimiento de desilusión en la novela está dado por cierta continuidad de la persecución nazi, convertida ahora en biopolítica, en organización de la vida.

En este sentido aparece una utopía que se puede pensar como modo de contrastar la producción biopolítica de normalidad. En un baño público Jäcki discute con Die Blume zu Saaron sobre la violencia y aparece en su discurso un elemento clave, la homosexualización mundial: “- (...) Para ser honesto, no me puedo imaginar la libertad más que como una gigante homosexualización mundial, dice Jäcki.” [“- (...) Ich kann mir die Freiheit, wenn ich ehrlich bin, nur als eine gigantische weltweite Verschwulung vorstellen, sagt Jäcki."] (221). Es importante notar que eso que traducimos por homosexualización en alemán no tiene la palabra Homosexuelle sino Schwul (Verschwulung) que, como ocurriría años después con la palabra queer, es también un insulto resignificado performativamente. La palabra Schwul no conlleva el binarismo que tiene la palabra "homosexual", sobre todo en 1971, cuando Fichte publica su novela. No se trata, en este sentido,

9 En este sentido, cobra importancia el nombre del médico patólogo Siegfried Graeff, que fue encargado de la disección de los cadáveres. Con su mención también se da cuenta de la continuación del nazismo después de la guerra, ya que fue un médico del nazismo que durante la posguerra continuó con sus tareas y, de hecho, siguió siendo galardonado. Por otra parte, la presencia de Gustaf Gründgens en el teatro, también mencionado en la novela, implica la continuación de los que fueron colaboradores del régimen nazi. De esta manera, mediante estas figuras, se marca también la continuidad del nazismo en el presente de la novela. Sobre las autopsias de Siegfried Graeff, el fascismo de la medicina y la continuidad del fascismo en Alemania, cf. Bandel. Sobre el tratamiento de los bombardeos en Hamburgo, cf. Böhme (163-182) y Gillett ("Huberts Imitationen"). 
de pensar la homosexualidad de manera identitaria sino, por el contrario, como una práctica sexual emancipatoria, es decir, que libera de los corsets identitarios, que libera de la homosexualidad entendida a partir del binario (homo/hetero). En este sentido, homosexualización implica ruptura de los binarios con los que pensamos la realidad social, particularmente los de sexogénero y, en este sentido, ruptura con la heterosexualidad entendida como régimen político. El mismo valor adquiere para Fichte la bisexualidad. En un encuentro con una conocida Jäcki expresa así su situación actual: "Yo sigo siendo bisexual" ["ich bin immer noch bi"] (196). La conjugación verbal de la frase no expresa una esencia, sino, podríamos pensar, un devenir, una sexualidad que experimenta y que, por eso, no puede fijarse en ninguno de los polos del binario ${ }^{10}$. Más que una identidad, la bisexualidad en Fichte y sus personajes implica la ruptura con la sexualidad identitaria y binaria.

Por otro lado, es interesante cómo para Fichte tratar estos temas también implica abordar el problema de la representación. Ciertos capítulos constituyen una deconstrucción del Yo, no solo en el sentido de la voz narrativa, sino también como una ruptura con la posibilidad de una identidad en términos esencialistas. Así, en el capítulo 34 podemos identificar a Detlev y a Jäcki como la misma persona: "Yo / ¿Cuál yo? / ¿Yo? / ¿Vos? / ¿Ud.? / ¿Cuándo yo escribo ‘yo' piensa usted en sí mismo o en mí? / ¿Jäcki? / ¿Detlev?” [Ich. / Wer ich? / Ich? / Du? / Sie? / Wenn ich "ich" schreibe, denken Sie an sich oder an mich? / Jäcki? / Detlev?] (69). Es interesante cómo esta identidad como performance se articula también con la cuestión de la memoria: "Yo me olvido. / Yo. / ¿Cuál yo? / ¿Detlev? / ¿Johnny? / Yo veo a Detlev, que interpreta a Johnny, de pie en el escenario y los espectadores ven a Johnny delante de su padre, y cuando a Detlev no le viene a la memoria la palabra correcta, entonces Johnny ha dejado de existir, sin haber muerto" [Ich vergesse. / Ich. / Wer ich? / Detlev? / Johnny? / Ich sehe Detlev, der Johnny spielt, auf der Bühne stehen und die Zuschauer sehen Johnny vor seinem Vater, und wenn Detlev das richtige Wort nicht einfällt, dann hat Johny aufgehört zu

10 La bisexualidad, como otros de los temas presentes en Fichte, va a ser reconsiderada en el amanecer de los estudios queer y desde el feminismo lesbiano como una forma de ruptura con el binario de sexo-género propio del (hetero)capitalismo. No era considerada una identidad sino una anti-identidad, un rechazo a tener que elegir un objeto de deseo fijo (Clausen 19). No era una integración de la homosexualidad y la heterosexualidad sino que consistía en una deconstrucción de la bicategorización de sexo-género (Däumer 95-6), un modo de desnaturalizar todo el sistema de sexo-género (Jagose 70). 
existieren, ohne gestorben zu sein.] (170). Johny, peronaje teatral encarnado por el Detlev actor, no existe más cuando éste deja de interpretarlo, así como Detlev deja de existir cuando Jäcki rechaza la ideología masculina que éste ha aceptado (Vocca 125). La relación entre la memoria y la identidad está en la base de toda autobiografía (Gillett, "Writing queer" 46) pero aquí se le escapa, prima la desmemoria, el olvido, por eso las imágenes que se le aparecen se vinculan con la sexualidad y los campos de concentración. ${ }^{11}$ Detlev imitación de Jäcki o Jäcki imitación de Detlev, no se puede determinar un origen, una esencia. Quizás, más que imitación, se trata de un éxtasis religioso de Detlev (Klaus 17). En medio del tratamiento deconstructivo del yo aparece el ritual mágico-religioso relacionado con el uso de belladona y la experiencia extracorporal de dejar de ser una persona:

Yo agrando mis ojos con belladona, dibujo mis cejas y la piel debajo de las pestañas para una mirada de tigre. Sobre la boca y la nariz trazo una colorida y grasienta raya transversal, como en el anuncio de "algo nuevo de Christian Dior", me pongo una peluca rubia y me visto con un pantalón de lentejuelas de una travesti operada que devino lesbiana, clavo el casco de plumas con cuernos de cartón, me pongo alas de flamenco, me cuelgo mi cinturón con pies de pato y ramitas coral, me echo encima el velo y me subo al caballo de madera del poeta bordado con perlas y espero a que los gallos sean sacrificados sobre mí y que las plumas con sangre se peguen en mi velo e imito a Detlev, que imita a Ifigenia de Tauris $(69-70)^{12}$.

11 Resulta interesante el análisis que en diferentes artículos ha hecho Gillett de la voz narrativa porque ve un cuestionamiento posmoderno y postestructuralista a la autobiografía como constatación del yo y de la subjetividad, ya que aquí la subjetividad e identidad aparecen cuestionadas. La subjetividad no remite a un origen esencial, sino que es imitación, en términos de Judith Butler, performance, iterabilidad que genera la ficción de un origen, de un interior elucidable (Gillett, "Eschewing the First").

12 "Ich vergrößere meine Augen mit Belladonna, verzeichne meine Brauen und die Haut unter den Wimpern zum Tigerlook. Über Mund und Nase ziehe ich bunte fettige Querstreifen, wie auf dem Reklamefoto von "etwas Neues bei Christian Dior...", setze mir eine blonde Perücke auf und ziehe den Paillettenhosenanzug des lesbisch gewordenen operierten Transvestiten an, stülpe den Federhelm auf mit den Papphörnern, binde mir Flamingoflügel um, behänge meinem Gürtel mit Entenfüßen und Korallenästen, werfe den Schleier über und besteige das perlenbestickte Schaukelpferd des Dichters und warte, daß die Hähne über mir geschlachtet werden und man die Daunen mit dem Blut an meinem Schleier festklebt und imitiere Detlev, der die Iphigenie auf Tauris imitiert.“(69-70) 
Lo que aparece en este caso es la realización mágico-religiosa, mediante la droga, de una performance drag. En ese sentido, es muy clara la alusión a Christian Dior. La moda se ha convertido en la forma esencialista normativa del deber ser. La moda es parte de la biopolítica, del régimen farmacopornográfico y la importancia de lo visual. Respecto a la mención a Christian Dior, Gillett comenta que "in the era of conspicuous consumption and the late capitalism, we define ourselves and our values by" (Gillett, "Writing queer" 46). El yo propio de la narración autobiográfica es visto aquí como la aplicación de maquillaje. Pero, detrás de ese maquillaje no hay una verdad del sujeto, una verdadera identidad, sino más maquillaje, capas superpuestas que conforman, como en la performatividad butleriana, la ficción de un rostro real, verdadero, de una identidad. Es interesante también contrastar con las performances teatrales de Detlev en las que el maquillaje y la ropa se utilizaban para performar su masculinidad-de hecho éste se avergüenza de tener que usar zapatos con taco para parecer más alto, $\mathrm{y}$, con eso, más masculino. Las performances teatrales en los espacios donde circula Jäcki, por el contrario, no refuerzan el binarismo de género sino que lo confrontan. Se trata de usos performáticos de desnaturalización del género y la sexualidad, así como de la naturaleza de la corporalidad. El teatro clásico y la tradición en la historia de Detlev aquí se convierten en performances pornográficas, en trabajo sexual, en disidencia política y sexual.

Aquí es importante resaltar que los modelos literarios de Fichte son Hans Henny Jahnn y Marcel Proust. De hecho, la concepción del tiempo en Fichte está retomada de este último. La temporalidad como artificio narrativo es puesta así en evidencia junto con el cuestionamiento del yo y la identidad: ¿Cuáles son las partículas más pequeñas del tiempo? / ¿Hay en el tiempo algo incluso más temporal? ¿Poseer, heredar, obtener, recibir... regalar, ¿tienen los objetos propiedades intemporales? ["Was sind die kleinsten Teile der Zeit? / Gibt es in der Zeit immer noch ein Zeitigeres? Besitzen, erben, erhalten, bekommen... geschenkt, haben Gegenstände Eigenschaften zeitlos?'] (27). La escritura se desarma, se desarticula, ya no sirve, se vuelve sinsentido, poética. Ambas son nuevas épocas, la posguerra y los disturbios del 68 y las revoluciones, pero en la conexión entre ambas, hay una decepción. De nada sirve, el tiempo es un vaivén contradictorio, cíclico, o conservador. La crítica en general se ha abocado más a la tarea de describir las similitudes y diferencias de los dos personajes principales, pero lo que se encuentra en el fondo es una concepción del sujeto no moderna, que se embebe en ritos mágico-religiosos desubjetivantes, despersonalizantes y destemporalizantes, 
vinculados con los cultos sincréticos afrobrasileños (Klauss 17). Más que con una puesta en abismo de la voz narrativa, la despersonalización se vincula con una forma mágica de entender la identidad, de entender al ser humano, que rompe con las formas modernas de la identidad y que lo relacionan con lo que ya por ese entonces eran ciertas conceptualizaciones postidentitarias del postestructuralismo que luego tomarían los estudios queer para deconstruir la sexualidad ${ }^{13}$.

\section{LA NUEVA REALIDAD Y LA SUBVERSIÓN MICROPOLÍTICA DE CARTACALO/A}

La sección 51 merece una mención aparte, ya que marca la finalización de la guerra para la historia de Detlev. Resulta la más extraña de la novela, justamente, porque en ella, en parte, se niega la forma novela, el género, y se pone en cuestionamiento la posibilidad de la escritura, o su capacidad. Se trata de una parodia o cita del Tractatus logico-philosophicus de Ludwig Wittgenstein, al menos de su estructura enumerativo-lógica ${ }^{14}$. Pero en Fichte la enumeración deviene en desorden a-lógico, de modo de dar cuenta de hasta qué punto el lenguaje se queda corto a la hora de poder captar, aprehender, la realidad. Sobre todo si se trata de que la Nueva Realidad, la liberación de fines de los sesenta y principios de los setenta no es más que una reelaboración de los viejos tiempos, como si, como afirma Preciado en Testo Yonqui, la sociedad disciplinar adquiriera a partir de la posguerra formas más sutiles de dominación, más micro, más biopolíticas:

1. sí, una nueva era ha comenzado.

2. CartacaloVla viene con el gorro tirolés en la mano

1. 1. (o incluso 1). La Nueva Realidad ha llegado.

0 (o meta-1). Diferentes estratos de la situación de Jäcki. Algunas observaciones incompletas sobre los números mismos parecen señalar

13 Sobre la relación Jäcki, Detlev y el Ich-Erzähler, cf. Mielke (108), Kreutzer (79), Ullrich, Weinberg. Los tres lo consideran una mediación entre el narrador y el autor.

14 Sobre la intertextualidad del capítulo 51 con Tractatus de Wittgenstein, cf. Klaus (99-108). 
que hay vinculaciones en lo no-natural, en el lenguaje no formalizado, que no pueden ser comprendidos por el esquema formal:

Fluctuaciones, paradojas, mentiras, sentimentalismos, melopoesía, cosas superfluas, antinomias, preferencias, arbitrariedades.

0 ((otra vez) Podría cifrar esta y la sección anterior con 0.1 y 0.2 y así rehacer la continuidad. Eso sería más falso que la contradicción: cero algo, cero otra cosa) (Este - el anterior-paréntesis es escribir sobre el escribir, incluso mientras escribo. No puedo escribir nada sobre el escribir mientras lo escribo, a menos que mi escritura no exprese nada sobre la relación entre el escribir y el objeto, sino escritura sólo sobre la escritura -sin objeto: Esta no es una oración larga, por ejemplo)

3. "Die Palette" está cerrado (81-2)

Este es el inicio de la sección 51. Se trata de un lenguaje que se desarma y de un sistema de clasificación llevado al absurdo. Lo que está parodiando son los sistemas de clasificación de la realidad y la estructura de saber/poder que le subyacen. Parecería sobrevolar la pregunta de si se puede recuperar la experiencia de la guerra, de los bombardeos de Hamburgo, de la disidencia sexual, del exterminio, etc., mediante el lenguaje o, más precisamente, mediante ciertas formaciones discursivas que constituyen la ciencia.

Lo que aparece en primer plano es una visión distorsionada de la realidad, que la tensiona, que la incomoda, para desrealizarla y desconfiar de hasta qué punto está construida por lenguajes, por discursos que la falsean o la moldean. En la enumeración caótica de la sección 51 aparecen y se recapitulan algunos puntos de los que se trata en la novela -tanto narrativos como de

15 “1. Ja, eine neue Zeit hat angefangen. / 2. Cartacalo/la kommt, den Sepplhut in der Hand. / 1.1. (oder noch mal 1.) "Die Neue Realität hat begonnen. / 0. (oder Meta-1.) Verschiedene Schichten der Situation Jäckis. Einige unvollständige Bemerkungen zu den Nummern selbst sollen andeuten, dass es in der unnatürlichen, nicht formalisierten Sprache Beziehungen gibt, die durch das formale Schema nicht erfasst werden können: / Schwanken, Paradoxa, Lüge, Sentimentalität, Melopoeia, Überflüssiges, Antinomien, Vorlieben, Willkür. / 0. ((noch mal) Ich könne diesen und den vorhergehenden Abschnitt mit 0.1 und 0.2 beziffern und dadurch die Kontinuität kitten. Das wäre falscher als der Widerspruch: einmal null so und einmal null so.) (Diese - die vorige-Klammer ist Schreiben über das Schreiben, fast während ich es schreibe. Über das Schreiben kann ich nichts schreiben, während ich es schreibe, es sei dann, mein Schreiben sage nichts aus über die Beziehungen vom Schreiben zum Gegenstand, sondern schreibt nur über Schreiben - gegenstandslos: Dies ist kein langer Satz, zum Beispiel.) / 3. "Die Palette" ist zu" (81-2). 
sentido (o contra-sentido). Por ejemplo la referencia a la mentira con que se describe el cuerpo de Jeff:

\subsection{5. ¿Estoy mintiendo?}

4.2.5.1. ¿La mentira de quién estoy mintiendo?

4.2.6.1. (y 1.1.4.2.) Resbalar en la bañera (...).Una impotencia nerviosa. Toser. Ni bien la tos se va, vuelven los dolores de cabeza. Por lo que uno siempre toma algo. El complejo de vitamina B ataca el corazón en los últimos tiempos. Tartamudeo y equivocación. $(94)^{16}$

Si la identidad es una mentira o, en términos de Butler, un acto de habla performativo, tal como afirma Gillett sobre el "yo" en esta novela de Fichte, entonces también tendríamos que ir más lejos y pensar en la corporalidad, en cómo esa performatividad, esa mentira, se hace carne, se vuelve micro, material, sustancias, se vuelve cuerpo. En el régimen farmacopornográfico de la posguerra no solo la identidad es una mentira, sino también el cuerpo. La represión, la cultura y la sociedad producen identidades prostéticas que implican la represión de una variedad de posibilidades. La naturaleza resulta, así, una compulsión, una violencia (ein Zwang):

4.4.2. En cuanto Jäcki piensa en su represión, vienen más y más represiones $(\ldots)$

¿Por qué Jäcki debe reprimirse a sí mismo sus deseos?

Sentido del deber.

Conciencia.

Mala.

Buena.

Demanda de que Jäcki se escinda en acusador y acusado. El acusado está en el underground y el acusador busca una ocupación y perdona indiscriminadamente a los que están cerca de él.

Lo natural - qué compulsión.

La masa.

La vida simple.

La no deformada.

La vanguardia. kommen die Kopfschmerzen wieder. So nimmt man immer irgendetwas ein. Der Vitamin-BKomplex greift in letzter Zeit das Herz an. Stottern und Vergreifen. (94) 
Ropa.

Anuncio.

Bircher-Bennermüsli.

Adjetivos y toda la ortografía.

¡Pero qué compulsión sería liberarse de la ortografía en cada palabra y de la gramática en cada frase! $(93-4)^{17}$

La naturaleza constituye así también una mentira que normativiza las vidas, las produce, las crea en un régimen farmaco-pornográfico, heteronormativo, el Hetero Capitalismo Mundial Integrado (Manada de Lobxs 60). Los cadáveres que analizaba Graeff ahora están en las vidrieras, son la nueva realidad, la liberación se convierte en moda; el disciplinamiento y sociedad de control, en farmacopornomegalópolis. El consumo capitalista (paso de tanato a bio política) produce subjetividades, normalidad y abyección:

4.5. Jäcki cree que es el aburrimiento. No Venus y sus fases. No el progreso o la reacción. No el curso de la historia.

Modas.

La guerra había llegado a ser aburrida. El New Look se llama paz. Uno lleva desde hace tiempo la no violencia y la democracia. Poco a poco las faldas son otra vez tan cortas como las faldas de las ayudantes de fuego antiaéreo. La paz se ha convertido en aburrida.

- Cuándo viene la guerra.

- Qué clase de guerra.

- La guerra. Cualquiera.

Las hebillas y las charreteras y las chapas de indentificación de cadáveres dominan las vidrieras de las boutiques.

1.1.3.2. La protesta tiene que ser divertida también. $(89-90)^{18}$

17 “4.4.2. Wie Jäcki über seine Unterdrückung nachdenkt, werden es immer mehr Unterdrückungen. (...) / Warum sollte Jäcki seine Wünsche vor sich selbst unterdrücken? / Pflichtgefühl./ Gewissen./Schlechtes./Gutes. / Forderungen, die Jäcki spalten in Ankläger und Angeklagten. Der Angeklagte geht in den Untergrund und der Ankläger sucht Beschäftigung und zeiht wahllos die Nächststehenden. / Das Natürliche - was für ein Zwang. / Die Masse. / Das einfache Leben. / Das nichtdeformierte. / Die Avantgarde. / Kleidung. / Reklame. / Bircher-Bennermüsli. / Adjektive und die gesamte Orthographie. / Aber was wäre es für ein Zwang, sich bei jedem Wort von der Orthographie und bei jedem Satz von der Grammatik zu befreien!" (93-4)

18 "4.5. Jäcki glaubt, daß es die Langweile ist. Nicht die Venus und ihre Phasen. Nicht Fortschritt oder Reaktion. / Nicht der Gang der Geschichte. / Moden. / Der Krieg war 
La Nueva Realidad es aburrida, la guerra se volvió aburrida, ahora la paz aburre, todo se vuelve moda, consumo capitalista, pero también consumo de cuerpos deseables, mostrables, exhibibles, la exhumación de cadáveres ahora es una vidriera de modas. En este contexto, el miedo no desaparece sino que persiste porque el poder toma formas más sutiles:

\author{
1.1.4. Miedo \\ La Nueva Realidad (...) \\ ¡Finalmente miedo de nuevo en Alemania! (84) ${ }^{19}$
}

En este contexto, es interesante tener en cuenta a uno de los personajes que aparece mencionado con frecuencia, Cartacalo/la. Se trata, en principio, de una drag-queen, pero también deviene trans, ya que se menciona una operación de cambio de sexo. Cartacalo/la es actor, actriz, prostituto, prostituta. No se lo/la puede identificar claramente como femenino o masculino. En la sección 51 reaparece la mención a Cartacalo/a en los distintos puntos del apartado 2 de la enumeración, en los que se la identifica de diferentes maneras. No se trata de una identidad, sino de una mutación, de alguien que va cambiando, de un devenir. Cartacalo/la es un chico ["Kerl" (82)], una drag-queen ["Damenimitator" (91)], un/a hermafrodita que se trata con electroshock (95). Pero también es la más oprimida y la más revolucionaria ["Unterdrückteste" y "revolutionärste" (96)], sobre todo en un contexto de 'aceptación' de lo gay y, con ello, de incipiente homonorma:

2.5. Empujar al escenario:

Cartacalo/la como la más oprimida. Cartacalo/la como el más revolucionario.

Oh sí, las piezas de teatro schwul están de moda. Ningún antiguo Nazi que no se vuelva humano ahora en las piezas schwul. $(96)^{20}$

langweilig geworden. Der New Look hieß Frieden. Man trug Nonviolence und Democracy lang. Allmählich werden die Röcke wieder kurz wie die Röcke der Flakhelferinnen. Frieden ist langweilig geworden. / - Wenn der Krieg kommt. / - Was für ein Krieg. / - Der Krieg. Irgendeiner. / Schnallen und Achselklappen und Leichenerkennungsmarken beherrschen die Schaufenster der Boutiquen / 1.1.3.2. - Protestieren muß ja auch Spaß machen" (89-90).

19 "1.1.4. Angst / Die Neue Realität. (...) / Endlich wieder Angst in Deutschland! (...)" (84).

20 "2.5. Auf die Schaubühne drängen: / Cartacalo/la als die Unterdrückteste. Cartacalo/ la als der Revolutionärste.

Ach ja, schwule Stücke sind Mode. Kein alter Nazi, der jetzt nicht in einem schwulen Stück menschlich wird.” (96) 
El sistema siempre necesita abyección para producir/delimitar la normalidad $\mathrm{y}$, en ese sentido, para producir/delimitar lo humano. En un contexto en el que el teatro gay está de moda, uno podría imaginar que hay una supuesta sensibilidad gay para el arte (identidad esencialista). Pero si se trata de maquinarias molares, mayoritarias (Deleuze y Guattari), entonces cuando el sistema heteropatriarcal 'acepta' o deja entrar a ciertas identidades, al mismo tiempo las segmentariza (Deleuze y Guattari). Y lo hace a cambio de algo, tienen que aportar un sentido, hacer sentido. No un sinsentido, de ninguna manera, que lo haga tambalear. Dentro del mismo apartado, 2.5, comienza a describirse una especie de pequeña escena teatral performática en la que actúa Cartacalo/la, claramente imposible de formar parte de las schwulen Stück que están de moda.

Carla predice la revolución mundial de los homosexuales y desenmascara la derogación del párrafo 175 como un engaño del stablishment. (...)

Revolución en Alemania. Cartacalo/la aparece en las barricadas y lee un llamamiento sobre el cambio de los niveles hormonales.

El punto culminante del espectáculo. ¡Muy majestuoso!

Transformación para hombres y mujeres.

Propósito de la vida. Oficina del partido.

Carla filosófica:

- En el negro odia el blanco a su padre, en los putos (Schwulen) el orangután a su abuelo

Total revolución permanente de la sociedad a través de procedimientos quirúrgicos. $(97)^{21}$

Cartacalo/la hombre, mujer, hermafrodita, trans, drag-queen. Su desafío a los binarismos la vuelven la más revolucionaria pero así también la más oprimida. Se desliza una crítica a la normalización gay, pues la abolición del 175 generó un establishment gay. En este contexto el accionar de

\footnotetext{
21 "Carla sagt die Weltrevolution der Homosexuellen voraus und entlarvt die Aufhebung des Paragraphen 175 als ein Täuschungsmanöver der Etablierten. (...) / Revolution in Deutschland. Cartacalo/la erscheint auf den Barrikaden und verliest einen Aufruf über die Veränderung des Hormonspiegels. / Höhepunkt des Schauspiels. Sehr majestätisch! / Umfunktionierung von Mann und Frau. / Lebensaufgabe. Parteibüro. / Carla philosophisch: / - Im Neger hasst der Weiße seinen Vater; im Schwulen den Orang-Utan, seinen Opa. / Totale permanente Revolution der Gesellschaft durch operative Eingriffe" (97).
} 
Cartacalo/la, sus performances pospornográficas y sexo-terroristas tienden a desestabilizar el sistema y, en ese sentido, podemos pensar, a anunciar un tipo de devenir queer. Cartacalo/la propone el uso de hormonas y de cirugía plástica no como modo de adaptarse al régimen farmacopornográfico sino como modo de desestabilizarlo. En este sentido, podemos pensar también algo similar a lo que hace Paul B. Preciado en Testo Yonqui con el uso de testosterona. El uso farmacopornoterrorista de las hormonas y de la cultura visual y pornográfica de Cartacalo/la, a partir de performances que se podrían considerar postpornográficas, puede ser entendido como un intento de revolución porno-terrorista, micropolítica, que se basa en el uso desestabilizador de las hormonas y las operaciones quirúrgicas.

Por otro lado, como ya se dijo, la novela también da cuenta de la estrategia de Jäcki por buscar el deseo por el atractivo Jeff. Pero esta búsqueda tiene un doble signo. Como ocurría con las representaciones de Tom de Finlandia en las paredes del bar schwul, la posibilidad de concreción del deseo por Jeff constituye un agenciamiento disidente. A la vez el cuerpo idealizado de Jeff -o, mejor, la idealización del cuerpo deseable encarnada en Jeff como objeto de deseo- también implica una normativización de lo que debe ser un cuerpo aceptable; es decir, que los cuerpos son productos de la máquina antropológica, que no son anteriores a la normativización, que son producciones del Hetero Capitalismo Mundial Integrado y que obedecen al binarismo del heteropatriarcado. La novela permite ver una tensión entre agenciamiento disidente y normalización fármaco-pornográfica. Esa es Die Neue Realität, un mundo en el que la homosexualidad puede ser permitida siempre que no desestabilice el sistema, por ejemplo, la bicategorización. En ese sistema el cuerpo de Cartacalo/la es inaceptable, ininteligible. Ahí radica la decepción que genera la novela en el contrapunto de las dos épocas y los dos personajes, que debería redundar en una contraposición, en una oposición clara que dé cuenta de la nueva época de la liberación. Sin embargo, lo que observamos es que el yugo se ha vuelto más sutil y más micropolítico. Todos formamos parte de él. Todos somos verdugos y sentenciados al mismo tiempo. Pero también, si no hay un afuera del poder en términos de Foucault, permite la resistencia y el agenciamiento disidente, como muestra el caso de la propuesta revolucionaria a nivel no-identitario y de monstruosidad hormonal y quirúrgica que implica Cartacalo/la.

Jeff, como los dibujos de Tom de Finlandia, es una mentira, una idealización. Si la novela, hacia el final, da cuenta de algún punto de liberación por parte de su protagonista doble Detlev/Jäcki -si la leemos a partir de un arco narrativo que implique que son la misma persona, el arco que va de Detlev a Jäcki-, 
ésta no se da por el hecho de conseguir el objeto de deseo buscado, de estar con Jeff, sino mediante la experiencia de la prostitución. Si hay una liberación esa no es Jeff sino el ejercicio de la prostitución que constituye una forma de empoderamiento (Dannecker 30). En Fichte, el amor resulta un discurso que también es normativo. La promiscuidad, en cambio, se convierte en un valor al punto que hacia el final de la novela si hay una liberación posible esta viene por el ejercicio de la prostitución, como modo emancipatorio del placer. Se trata, en este sentido, de "emanciparse de la emancipación" (Manada de Lobxs 34). Jäcki elige la prostitución a pesar de seguir siendo social y moralmente condenada y perseguida, la prostitución es lo que le permite el agenciamiento personal como forma de escapar a la normativización sexogenérica, es decir, como forma de desaprender lo aprendido por Detlev mediante la imitación. Quizá no se trate de una liberación en el sentido de descubrimiento del deseo/sexualidad reprimida (esencialista primigenia) sino de la producción de nuevos placeres.

\section{CONCLUSIONES: JÄCKI, DETLEV, CARTACALO/A, FICHTE}

Publicada en 1971, la tercera novela de Hubert Fichte, Detlevs Imitationen "Grünspan" pasó bastante inadvertida, pero en ella aparecen cuestionamientos a la heterosexualidad como régimen político que son de una enorme actualidad hoy en día. En Fichte encontramos una enorme complejidad en el tratamiento de la sexualidad que va de la mano también con la ruptura del sentido, del lenguaje y del género novela, de la identidad del personaje y del narrador (Detlev / Jäcki) y de la temporalidad cronológica. Si todo lenguaje está inmerso en una relación de poder, no se trata de renunciar a él sino de ejercer la resistencia mediante su dislocamiento. La temporalidad en esta novela rompe con la unidad opositiva binómica pasado/presente: el tiempo en Detlevs Imitationen "Grünspan" no es cronológico, los distintos devenires temporales se solapan y hacen conexiones entre sí, sin una perspectiva teleológica. La historia del personaje, a diferencia de la tradición del Bildungsroman, no es una evolución, sino un devenir. La novela se convierte así en un mapa más que un calco (Deleuze y Guattari 1988) ${ }^{22}$. No hay génesis, ni origen, solo

22 En Mil mesetas, Deleuze y Guattari oponen el principio de cartografía al de calcomanía. Según ellos el rizoma se asocia al mapa y no al calco, pues el calco es una copia, 
experiencia que no puede trasladarse a la escritura sin ponerla en crisis, sin hacerlo de forma rizomática. La estructura de la novela, más que la lógica del conocimiento hegemónico o científico, sigue la de la magia, la del ritual mágico-religioso. Mediante estas rupturas, Detlevs Imitationen "Grünspan" genera también cuestionamientos a la moralidad, a la sexualidad y el género binarios y propicia formas de resistencia y puntos de fuga performáticos y micro-políticos, hormonales y pornográficos, anticipándose a la caracterización del sexo-género a partir de la posguerra que realizara Paul B Preciado como régimen farmacopornográfico. De esta forma, es posible ejercer la resistencia a la producción de normalidad del Hetero Capitalismo Mundial Integrado. Podríamos pensar, así, como una utopía disidente esa homosexualización mundial ["eine gigantische weltweite Verschwulung" (221)] de la que habla Fichte. Eso es lo único que puede significar la libertad para Jäcki en Detlevs Imitationen "Grünspan”. Podríamos decir, entonces, que la única y verdadera liberación radica en una queerización (Verschwulung) mundial que, podríamos pensar, consiste, como modo de combatir el régimen farmacopornográfico, en una combinación de revolución molar y molecular. Como comenta Paul B. Preciado,

La molarización es una condición de la acción política colectiva, de la producción de una cierta puissance (potencia, más que poder) d'agir. Curiosamente, cuando escribo molarización el software MSWord se empeña en transformar la palabra en "dolarización”, quién sabe si consciente de las actuales técnicas de mercantilización de la identidad. La cuestión es cómo atravesar la molaridad identitaria (sexual, nacional, racial) sin hacer de la identidad el fin último de la acción política. Es necesario hacerse cargo de la propia molaridad (la opresión, en este sentido, actúa como un catalizador identitario) para poder moverse hacia un devenir molecular, inframolar y posidentitario. Para mí esta transición indica el pasaje desde una política de la representación hacia una política de la experimentación, pero también desde una obsesión por la visibilidad como condición de la emancipación hacia

una reproducción, tiene una estructura profunda y un eje genético. El mapa, en cambio, está "totalmente orientado hacia una experimentación que actúa sobre lo real", el mapa construye, "es abierto, conectable en todas sus dimensiones, desmontable, alterable, susceptible a distintos montajes". Una de las características del calco, como el rizoma, "es la de tener siempre múltiples entradas" (Deleuze y Guattari 17-8). 
un devenir imperceptible... como garantía de las micropolíticas. (Preciado, "Entrevista" 401)

Esa combinación entre revolución molar y molecular es la que intentamos leer en la década de la liberación gay-lésbica en la República Federal de Alemania a partir de la novela de Fichte. Ya desde el inicio de los setenta, no se trataba ni de sostener como fin último la identidad ni de negarla, sino de su uso como estrategia política para combinar con otras formas de revolución micropolítica, con otras políticas de los afectos y de la sexualidad como experimentación, de la producción de placeres y modos de vida nuevos. Así, la homosexualidad -y, más radicalmente, la sexualidad schwul- no se trata de una enunciación de identidad esencialista sino que constituye una forma de la acción molecular, del contagio, del devenir enfermedad, vampiro, animal. Se trata de una utopía molecular, microprostética-como en el caso de Cartacalo/a- o, en términos de Preciado, una utopía anal que nace en los años setenta y se institucionaliza en la perspectiva queer a partir de los noventa.

\section{BIBLIOGRAFÍA}

Agamben, Giorgio. Homo Sacer I. Valencia: Pretextos, 1998.

Bandel, Jan-Frederik. "Versuch über den Zauber. Zu Hubert Fichtes Prosaverfahren". Forum. Homosexualität und Literatur, $\mathrm{N}^{\circ} 41,2002$. 47-74.

Böhme, Hartmut. Hubert Fichte. Riten des Autors und Leben der Literatur. Stuttgart: J.B. Metzlersche Verlagsbuchhandlung, 1992.

Butler, Judith . El género en disputa. El feminismo y la subversión de la identidad. Barcelona: Paidós, 2007.

Clausen, Jan. "My Interesting Condition". Out/Look: National Lesbian and Gay Quarterly 7, 1990. 11-21.

Däumer, Elizabeth. "Queer Ethics; or, The Challenge of Bisexuality to Lesbian Ethics". Hypatia 7, 4 (1992): 91-105.

Dobler, Jens. "Schwule Lesben". Rosa Radikale. Die Schwulenbewegung der 1970er Jahre. Eds. Andreas Pretzel y Volker Weiß. Hamburg: Männerschwarm Verlag, 2012. 113-123.

Deleuze, Gilles. "Posdata sobre las sociedades de control". El lenguaje literario $\mathrm{T}^{\mathrm{o}} 2$. Ed. Christian Ferrer. Montevideo: Nordan, 1990.

y Félix Guattari. Mil mesetas: capitalismo y esquizofrenia. Valencia: Pre-textos, 1988.

Fichte, Hubert. Detlevs Imitationen "Grünspan": Roman. Frankfurt am Main: Fischer Taschenbuch, 2005. 
Gillett, Robert. "Huberts Imitationen. Intertextualität in und um Grünspan". Medium und Maske. Die Literatur Hubert Fichtes zwischen den Kulturen. Eds. Hartmut Böhme y Nikolaus Tiling. Stuttgart: M \& P, 1995. 303-333.

“«Ein Verständigungstext ist das gewiß nicht». Fichte und queer”. Ethno/Graphie. Reiseformen des Wissens. Eds. Peter Braun y Manfred Weinberg. Tübingen: Gunter Narr Verlag, 2002.149-191.

"Fichte, Detlevs Imitationen Grünspan". Landmarks in the German Novel (2). Eds. Peter Hutchinson y Michael Minden. Oxford: Peter Lang, 2010. 43-60.

"Writing queer performance: Hubert Fichte's inimitable Imitations". Sexualities $\mathrm{N}^{\mathrm{o}} 15$ (2012): 42-52.

"Eschewing the First Person: Post-Subjective Autobiography in Hubert Fichte and his Geschichte der Empfindlichkeit/History of Sensitivity". European Journal of Life Writing, Vol IV (2015): 37-55.

Guattari, Félix. Plan sobre el planeta. Capitalismo mundial integrado y revoluciones moleculares. Madrid: Traficantes de Sueños, 2004.

Gundermann, Christian. Transforming modernity's primitivisms: Hubert Fichte's queer ethnography in the postcolonial Latin American context. PhD Dissertation Cornell University 511, 1999.

Hergemöller, Bernd-Ulrich. Mann für Mann. Ein biographisches Lexikon. Frankfurt a. M.: Suhrkamp, 2001.

Jagose, Annamarie. Queer theory: an introduction. New York: New York University Press, 1996.

Klaus, Martin. Intertextualität und ihre Funktionen in Hubert Fichtes Detlevs Imitationen “Grünspan”. Bielefeld: Universität Bielefeld, Fakultät für Linguistik und Literaturwissenschaften, 2006.

Kreutzer, Leo. "Hubert Fichte oder: Für eine Ästhetik der Antiquiertheit des Menschen". Literatur und Entwicklung. Studien zu einer Literatur der Ungleichzeitigkeit. Frankfurt a. M.: Fischer Taschenbuch, 1989. 76-94.

Madsen, Bertil. Auf der Suche nach einer Identität: Studien zu Hubert Fichtes Romantetralogie, Das Waisenhaus, Die Palette, Detlevs Imitationen “Grünspan” Versuch über die Pubertät. Stockholm: Almqvist \& Wiksell, 1990.

Manada de Lobxs. Foucault para encapuchadas. Buenos Aires: Milena Caserola, 2014.

Mielke, Rita. "Doppelperspektivisches Erzählen bei Hubert Fichte. Eine Untersuchung zu zwei frühen Erzählungen und dem Roman 'Das Waisenhaus'”. Text und Kritik 72 (1981): 108-111. München.

Popp, Wolfgang. Männerliebe. Homosexualität und Literatur. Stuttgart: J.B. Metzler, 1992. Preciado, Paul B. Testo yonqui: sexo, drogas y biopolítica. Buenos Aires: Paidós, 2014. Manifiesto contra-sexual. Madrid: Opera Prima, 2002.

"Entrevista com Beatriz Preciado" (por Jesús Carrillo). cadernos pagu (28), janeirojunho de 2007, 2007. 375-405.

"Terror anal: apuntes sobre los primeros días de la revolución sexual". Guy Hocquenghem y Beatriz Preciado. El deseo homosexual (con Terror anal). Barcelona: Melusina, 2009. 
Pretzel, Andreas y Volker Weiß. "Die Schwulenbewegung der 1970er Jahre. Annäherungen an ein legendäres Jahrzehnt". Rosa Radikale. Die Schwulenbewegung der 1970er Jahre. Eds. Andreas Pretzel y Volker Weiß. Hamburg: Männerschwarm Verlag, 2012. 9-28.

Ullrich, Gisela. “Hubert Fichte: Detlevs Imitationen 'Grünspan', 197”. Identität und Rolle. Probleme des Erzählens bei Johnson, Walser, Frisch und Fichte. Stuttgart: Klett, 1977. 64-78.

Vocca, Robert Thomas. Rites of Passage and the Construction of Masculinity in Hubert Fichte's Das Waisenhaus, Detlevs Imitationen Grünspan, Die Palette, and Versuch Über Die Pubertät. Thesis, Doctor of Philosophy, Ohio State University, 1993.

Vollhaber, Tomas. Das Nichts, die Angst, die Erfahrung. Untersuchung zur zeitgenössischen schwulen Literatur. Berlin: Verlag Rosa Winkel, 1987.

Wangenheim, Wolfgang von. Hubert Fichte. München: Verl. Edition Text und Kritik, 1980.

Weinberg, Manfred. Akut, Geschichte, Struktur: Hubert Fichtes Suche nach der verlorenen Sprache einer poetischen Welterfahrung. Bielefeld: Aisthesis, 1993. 